\title{
Cryptolepine consolidates its anticancer potential by increasing the anti-cancer pathway genes and decreasing that of pro-cancer pathway genes
}

Patrick Williams Narkwa ( $\square$ patricknarkwa1@gmail.com )

Kwame Nkrumah University of Science and Technology https://orcid.org/0000-0003-2490-7902

Seth Agyei Domfeh

University of Ghana

Gordon Awandare

University of Ghana

Mohamed Mutocheluh

Kwame Nkrumah University of Science and Technology College of Science

\section{Research Article}

Keywords: Cryptolepine, Anticancer, STAT3, IRF1, HIF-1a, Progesterone receptors, HEK 293 cells

Posted Date: February 9th, 2021

DOI: https://doi.org/10.21203/rs.3.rs-133186/v3

License: (c) (i) This work is licensed under a Creative Commons Attribution 4.0 International License. Read Full License 


\section{Abstract}

Background: Cancers are one of the commonest causes of deaths globally. Reports indicate that greater than sixty percent of cancers in the world occur in low and middle-income countries with about seventy percent of all cancer deaths occurring in these regions. Conventional cancer treatments involve surgery, radiotherapy, chemotherapy, etc. However, the negative side effects such as high cost and toxicity associated with these treatment options have increased the demand for less toxic and less expensive anti-cancer drugs from natural sources. One of such natural products believed to have anti-cancer potential is cryptolepine (CRYP), an alkaloid extracted from the roots of Western and Central African plant Cryptolepis sanguinolenta. In addition to its anti-cancer potential, CRYP has been reported to possess a myriad of pharmacological activities. However, the mechanisms underlying the anti-cancer and pharmacological activities of CRYP have not been fully explored.

Methods: We screened 45 immune and cancer signalling pathways for their regulation following treatment with CRYP using the dual-luciferase based Cignal Finder Multi-Pathway Reporter Arrays to pinpoint which pathways are regulated by CRYP. Additionally, the effects of CRYP on the transcript levels of interferon regulatory factor 1 (IRF-1), progesterone receptor (PR), hypoxia-inducible factor-1 alpha (HIF1a) and signal transducer and activator of transcription 3 (STAT 3) were assessed by real-time quantitative polymerase chain reaction (RT-qPCR).

Results: We observed that of the 45 immune and cancer signalling pathways screened, nine were upregulated while twenty-seven were down-regulated by CRYP. However, CRYP had no effect on nine of the pathways screened. We also observed that CRYP induced an increase in the transcript levels of IRF1 and PR but decreased that of HIF1- $a$ and STAT3.

Conclusion: The upregulation of human anti-cancer pathway genes including IRF-1 and PR and concomitant down-regulation of pro-cancer pathway genes including HIF1- $a$ and STAT3 suggest additional mechanisms through which CRYP could exhibits its anti-cancer potential.

\section{Background}

Cancers have been identified as one of the commonest causes of deaths globally. Estimates from the International Agency for Research on Cancer (IARC) predicts that the global incidence of cancer is expected to surge upwards from 14 million per year to about 22 million per year by the year 2030 (1). During the same period, cancer-induced deaths are expected to rise from an estimated 8.2 million to 13 million per year. It has been reported that greater than $60 \%$ of all cancer cases in the world occur in low and middle-income countries with about $70 \%$ of all cancer deaths occurring in these regions (1). Cancers are mostly caused by lifestyle behaviours such as abuse of tobacco and alcohol, inadequate intake of fruit and vegetable on a regular basis, obesity and lack of physical activity. In addition, certain chronic infections from hepatitis B virus (HBV), hepatitis $\mathrm{C}$ virus (HCV) and some types of human papillomavirus (HPV) may also increase the risk of cancer (2). 
Traditional interventions that are employed in the treatment of cancers include surgery, radiotherapy, chemotherapy, hormone therapy, immune therapy, targeted therapy and psychosocial support(2). Aside from the high costs that are usually associated with these treatment options, toxic side effects associated with cancer chemotherapy and radiation therapy have opened the avenues for research into the discovery of new anticancer agents from plants and other natural sources. Making cancer treatments more effective and less expensive especially in resource-limited countries including Ghana will greatly reduce cancer-induced deaths even in situations where health-care services are not well developed. In view of that natural products from plant sources that are basically used in traditional medicines are being explored as one of the major sources of cancer chemo-preventive drug discovery. One of such plant products that is being considered as a potential anticancer agent is CRYP.

CRYP is an alkaloid that is extracted from the roots of a plant called Cryptolepis sanguinolenta. This plant is common in the West and Central parts of Africa. CRYP has been widely reported to exhibit a myriad of pharmacological and biological properties which include anti-malarial (3), anti-bacterial(4), anti-fungal(5) and anti-hyperglycaemic $(6,7)$ under different in vitro and in vivo conditions. In addition to these many pharmacological and biological activities, CRYP has also been reported to have antiinflammatory activity in different animal model systems $(8,9)$. The anti-inflammatory activity of CRYP has led some researchers to evaluate the anticancer potential of CRYP.

Some studies have reported that CRYP and its derivatives could exhibit their anticancer properties by directly binding to DNA and inhibiting DNA replication and also inhibiting the functions of topoisomerase II (10-12). In fact, studies have shown that several anti-cancer agents mechanistically work by inhibiting topoisomerase II enzyme and that inhibition of topoisomerase II induces apoptosis (13). CRYP has also been reported to have significant effects on the functional ability of p53 one of the key tumour suppressor proteins (14). For example, Zhu and Gooderham (2006) reported that CRYP induces the accumulation of p53 protein in human lung adenocarcinoma A549 cell lines (15). The increase in the levels of p53 protein following CRYP treatment has been reported to enhance DNA repair mechanisms of the affected cells $(16,17)$. Caspases are the key architects of apoptosis and CRYP has been reported to significantly activates caspase 3 but CRYP-induced activation of caspase 8 has been reported to be minimal suggesting that CRYP may induce apoptotic cell death partly via the mitochondrial pathway (15, 18). Bcl-2 is a protooncogene and reports have indicated that treatment of cells with CRYP results in inhibition of Bcl-2 activity resulting blockage of apoptotic cell death $(15,18)$.

In spite of the these reported anti-cancer potential, how CRYP regulates various genes including the oncogenic ones and those with anti-cancer activity have not been fully explored. We therefore, used the Cignal Finder 45 Pathway Reporter Array plate (Qiagen and SA Biosciences, USA) to simultaneously assess the effects of CRYP on 45 different signalling pathways that cover research areas such as cancer, immunology, development and toxicology to pin-point which pathways are affected by CRYP. Based on the screening data, IRF1, PR, HIF1- $a$ and STAT3 target genes were selected and the effects of CRYP on the transcript expression of these selected genes were confirmed using RT-qPCR. 
We report that treatment of human embryonic kidney 293 (HEK 293) cells with CRYP increased the transcript expression levels of IRF-1 and PR but decreased that of HIF1-a and STAT3. The outcome of the current study could offer promising avenues for further research into the development of CRYP as a novel anticancer agent. Achieving this feat would improve the treatment success of cancers and increase the chances of survival of cancer patients in Ghana and other low- and middle-income countries.

\section{Materials And Methods}

\section{Reagents and chemicals}

The CRYP used in the study was donated by Prof. Kwesi Mensah Boadu, Faculty of Pharmacy and Pharmaceutical Sciences, Kwame Nkrumah University of Science and Technology (KNUST), Kumasi, Ghana. It was dissolved in phosphate buffered saline (PBS) to a stock concentration of $43050 \mu \mathrm{M}$, filter sterilized and divided into aliquots, wrapped in aluminum foil and stored frozen at $-20^{\circ} \mathrm{C}$ until used. The CRYP stock solution was diluted to the desired concentration in normal growth medium when necessary. The foetal bovine serum (FBS) (cat \# F2442) was purchased from Sigma-Aldrich, USA. Dulbecco's Modified Eagles Medium (DMEM) (high glucose, L-glutamine, sodium pyruvate) (cat \# 1-26F58-1) was purchased from BioConcept Ltd, Switzerland. Minimum essential medium (MEM) non-essential amino acids (NEAA) (cat \# 0823) was purchased from ScienCell, USA. Opti-MEM reduced serum medium (cat \#31985-070) was purchased from Gibco Life Technologies, USA while penicillin-streptomycin (cat \#15140) was purchased from Gibco by Invitrogen, UK. Thiazolyl blue tetrazolium bromide powder (MTT powder) (cat \# M5655-1G) was purchased from Sigma Aldrich, USA. The MTT powder was dissolved in PBS to a stock concentration of $5 \mathrm{mg} / \mathrm{ml}$, filter sterilized and divided into working aliquots, wrapped in aluminum foil and stored at $-20^{\circ} \mathrm{C}$ until used. Isopropyl alcohol (> 99.5\% purity, cat \# 67-63-0) was purchased from Dae-Jung Chemicals and Metals, Siheung-Si, Gyeongii, Korea. Cignal Finder Reporter Array Plates (cat \# CCA-901L) were purchased from SA Bioscience, USA. Attractene Transfection Reagent (cat \# 301005) was purchased from Qiagen, USA. The Dual Luciferase Reporter Assay System (cat\# E1960) was purchased from Promega, USA.

\section{Cell culture}

The HEK 293 cells (cat \# CRL-1573) used in the study was purchased from the American Type Culture Collection (ATCC), USA. The cells were grown in DMEM high glucose-containing L-glutamine, sodium pyruvate supplemented with $10 \% \mathrm{v} / \mathrm{v}$ heat-inactivated FBS, $1 \% \mathrm{v} / \mathrm{v}$ MEM non-essential amino acids, 100 $\mathrm{IU} / \mathrm{ml}$ of penicillin and $100 \mu \mathrm{g} / \mathrm{ml}$ of streptomycin. The cultures were maintained at $37^{\circ} \mathrm{C}$ in $5 \%$ carbon dioxide $\left(\mathrm{CO}_{2}\right)$ under humidified condition.

\section{Cytotoxicity assay}

HEK 293 cells were grown to about $60 \%$ confluence and then treated with increasing concentrations of CRYP $(0-10 \mu \mathrm{M})$. The cytotoxic effect of CRYP was evaluated using MTT assay at 24, 48- and 72-hours post-treatment following the manufacturer's instruction. Briefly, the cell culture media containing the 
CRYP was carefully removed. Fifty microliters $(50 \mu \mathrm{l})$ of serum-free media and $50 \mu \mathrm{l}$ of MTT solution were added into each well. Solvent control wells or blank wells containing $50 \mu$ of the MTT reagent and $50 \mu l$ of cell culture media (no cells) were included in the assay. The plates were incubated for 3 hours at $37^{\circ} \mathrm{C}$. After incubation, $150 \mu$ l of isopropyl alcohol (MTT solvent) was added into each well. The plates were wrapped in aluminum foil and shaken on Edmund Buhler orbital shaker (Edmund Buhler GmbH, Germany) for 15 minutes. The optical density (OD) of the wells was read at $590 \mathrm{~nm}$ using iMark Microplate Reader (Bio-Rad, USA).

\section{Cignal Finder 45-Pathway Reporter Array and Reverse Transfection}

We used the Cignal Finder 45 Pathway Reporter Array Plate (Qiagen and SA Biosciences, USA) to simultaneously assess the effects of CRYP on 45 different signalling pathways. These 45 signalling pathways cover research areas such as cancer, immunology, development and toxicology. The Cignal Finder 45-Pathway Reporter Array has 45 pathway reporters dried and coated down in duplicate wells of the 96-well plate with the remaining 6-wells containing positive and negative controls. Each reporter consists of an inducible transcription factor-responsive construct and a constitutively expressing Renilla luciferase construct. The inducible transcription factor-responsive construct encodes the firefly luciferase reporter gene and monitors both the increase and decrease in the activity of the coupled transcription factor in a said signalling pathway while the Renilla construct encodes the Renilla luciferase reporter gene which serves as an internal control to which firefly activity is normalized. To determine the effects of CRYP on the 45 signalling pathways, the reporter constructs were reverse transfected into HEK 293 cells following the manufacturer's instruction. Briefly $50 \mu \mathrm{l}$ of Opti-MEM ${ }^{\circledR}$ was added into each well of the Cignal Finder Array plate to resuspend the reporter constructs. The plate was incubated at room temperature for 5 minutes. The Attractene transfection reagent was diluted in Opti-MEM after which $50 \mu l$ of diluted Attractene was added into each well containing $50 \mu$ of the diluted nucleic acids. Cells were suspended to a density of $8 \times 10^{5}$ cells $/ \mathrm{ml}$ in Opti-MEM ${ }^{\circledR}$ containing $10 \%$ of FBS and $0.1 \mathrm{mM}$ NEAA and $50 \mu \mathrm{l}$ of the cell suspension was added to each well of the Cignal Finder Array plate containing the reporter constructs and the transfection reagent. The cells were incubated at $37^{\circ} \mathrm{C}$ in a $5 \% \mathrm{CO}_{2}$ incubator for 18 hours. Following reverse transfection, the cells were treated with assay medium (Opti-MEM ${ }^{\circledR}$ supplemented with 0.5\% FBS, 0.1 mM NEAA, $100 \mathrm{U} / \mathrm{ml}$ Penicillin and $100 \mu \mathrm{g} / \mathrm{ml}$ Streptomycin) containing $5 \mu \mathrm{M}$ CRYP for another 18 hours. A control experiment in which the cells were reverse transfected but not treated with cryptolepine was done in parallel with the treated experiment. The cells were lysed passively and dual luciferase expression was determined using the dual luciferase reporter assay system (Promega, USA, cat no E1960) following the manufacturer's protocol. After preparing the cell lysates, 20 $\mu \mathrm{l}$ of the aliquot was employed for luminescence measurement using Berthold Orion luminometer (Berthold Detection Systems, Germany).

\section{Reverse transcriptase-quantitative polymerase chain reaction (RT-qPCR)}

HEK 293 cells were cultured and treated with increasing concentrations of CRYP (0-5 $\mu \mathrm{M})$ for 24 hours. Total RNA was then extracted using the Gene JET RNA purification kit (Thermo Scientific, Germany) 
following the manufacturer's instruction. The quantity and the purity of the total RNA was verified by spectroscopy (Nano Drop 1000, Thermo Scientific). The purity was later confirmed by $1 \%$ agarose gel electrophoresis using ethidium bromide as a stain. The total RNA was converted to cDNA as we previously described (19). The cDNA was stored frozen at $-80^{\circ} \mathrm{C}$ until used in the qPCR. IRF1, PR, HIF1-a and STAT3 target genes were amplified using the Maxima Probe/Rox qPCR master mix (Thermo Scientific, Germany). The primers and probes used were designed and synthesized by Biomers, Germany (Table 1). The probes of the target genes and the endogenous control Beta-actin (B-actin) were labelled with different fluorescent reporter dyes at the $5^{\prime}$ end and quencher dyes at the $3^{\prime}$ end and this allowed the target genes to be amplified in the same tube in a duplex qPCR reaction. After optimizing the primer and probe PCR conditions, a duplex qPCR was performed in a $20 \mu \mathrm{l}$ reaction volume that contained $0.3 \mu \mathrm{M}$ forward and reverse primers of the target genes, $0.2 \mu \mathrm{M}$ of the target probes, $0.2 \mu \mathrm{M}$ forward and reverse primers of the B-actin, $0.2 \mu \mathrm{M}$ of the B-actin probe and $2.0 \mu \mathrm{l}$ of $1: 5$ dilution of the cDNA samples. The qPCR cycling conditions were as we previously described(19). The qPCR reaction products were analyzed using the Applied Biosystems StepOne Plus Manager Software. The relative quantification of the target genes was calculated using the Relative Standard Curve method.

\section{Statistical Analysis}

All experiments were conducted three (3) times at different times in duplicate or triplicate wells where applicable. Data were entered into an excel spread sheet and then analysed using excel and the appropriate data management software. One-way Analysis of variance (ANOVA) and student $t$-tests were used to analyse the level of significance between the treated and untreated groups where applicable. Pvalue $\leq 0.05$ was considered as statistically significant.

Table 1: Primers and probe sequences 


\begin{tabular}{|c|c|c|}
\hline Target genes & Sequences of primers $\&$ probes & Fluorophores \\
\hline IRF-1 & $\begin{array}{l}\text { Forward primer:5'-TTTGTATCGGCC } \\
\text { TGTGTGAATG-3' } \\
\text { Reverse primer:5'-AAGCATGGCTGG } \\
\text { GACATCA-3' } \\
\text { Probe:5'-CAGCTCCGGAACAAACAG } \\
\text { GCATCCTT-3' }\end{array}$ & 5’FAM-3’BHQ1 \\
\hline PR & $\begin{array}{l}\text { Forward primer:5'-AGAAATGACTGC } \\
\text { ATCGTTGATAAAATC-3' } \\
\text { Reverse primer:5'-GGACCATGCCAG } \\
\text { CCTGAC-3' } \\
\text { Probe:5'-TCTGCCCAGCATGTCGCC } \\
\text { TTAGAAAGTGC-3' }\end{array}$ & 5’FAM-3’BHQ1 \\
\hline HIF1- $\alpha$ & $\begin{array}{l}\text { Forward primer:5'-CAGAGCAGGAAA } \\
\text { AGGAGTCA-3' } \\
\text { Reverse primer:5'-AGTAGCTGCATGA } \\
\text { TCGTCTG-3' } \\
\text { Probe:5'-ACTAGCTTTGCAGAATGCT } \\
\text { CAGAGAA-3' }\end{array}$ & 5’FAM-3'BHQ1 \\
\hline STAT3 & $\begin{array}{l}\text { Forward primer:5'-GGAGCAGAGATG } \\
\text { TGGGAATG-3' } \\
\text { Reverse primer:5'-GTGGGTCTCTAG } \\
\text { GTCAATCTTG-3' } \\
\text { Probe:5'-AGTCTCGAAGGTGATCAG } \\
\text { GTGCAG-3' }\end{array}$ & 5’FAM-3'BHQ1 \\
\hline B-actin & $\begin{array}{l}\text { Forward primer: 5'-TCACCCACACTG } \\
\text { TGCCCATCTACGA-3' } \\
\text { Reverse primer:5'-CAGCGGAACCGC } \\
\text { TCATTGCCAATGG-3' } \\
\text { Probe:5'-ATGCCCCCCCCATGCCATC } \\
\text { CTGCGT-3' }\end{array}$ & 5’HEX-3’TAMRA \\
\hline
\end{tabular}

\section{Results}

\section{Cytotoxicity of CRYP}

We first evaluated the cytotoxic effects of different concentrations of CRYP on HEK 293 cells using MTT assay. It was observed that CRYP decreased the viability of HEK 293 cells in a dose-dependent manner after exposure of HEK 293 cells to CRYP concentrations of up to $10 \mu \mathrm{M}$ for 24,48 and 72 hours (Fig. 1). 
For the following succeeding experiments, CRYP concentrations of up to $5 \mu \mathrm{M}$ were used and with an incubation period of 24 hours. These concentrations were selected based on the facts that more than $80 \%$ of the cells survived at those concentrations at 24 -hour post-incubation (Fig. 1 ). An additional Table file 1 containing mean ( \pm standard deviation) values from all experimental replicates gives more details (see Additional file 1) as error bars are too small to show on Figure 1.

Fig. 1: HEK 293 cells and cytotoxicity of CRYP. CRYP cytotoxicity was evaluated by MTT assay on HEK 293 cells treated with CRYP $(0-10 \mu \mathrm{M})$ for 24,48 and 72 hours. The viability of cells was calculated as the ratio between CRYP-treated cells and non-treated cells (equal volume of PBS replacing CRYP). Data are presented as mean and standard deviation of three independent experiments each performed in triplicate wells, $p$-value $=0.03$ as determined by one-way ANOVA. The error bars represent the standard deviation among the three independent experiments but are too small to show.

\section{CRYP differentially regulates 45 signaling pathways}

We next utilized the Cignal Finder 45 Pathway Reporter Array to simultaneously screen for the effects of CRYP on the relative activity of 45 signaling pathways following CRYP treatment of HEK 293 cells after reverse transfection of the reporters into the HEK 293 cells. The relative fold change values were obtained by dividing the normalized luciferase activities of each treated pathway-focused reporter by the normalized luciferase activity of the untreated pathway reporter. Of the 45 signaling pathways screened, nine (first 9 bars on the left; Fig.2) were upregulated by CRYP while twenty-seven (the last 27 bars on the right; Fig.2) were downregulated by CRYP. CRYP had no detectable effects on nine ( 9 bars at the middle between the upregulated and the downregulated bars; Fig.2) of the pathways screened. The criteria for categorization of the signaling pathways into up-regulated, down-regulated and no effects were as follows: signaling pathways that had relative fold change values $>1.5,<0.7$ and $=0.7-1.5$ were considered to be up-regulated, down-regulated or unaffected respectively (Fig. 2). An additional Table file 2 containing the reporters, signaling pathways, transcription factors and the fold change values shows more details (see Additional file 2).

Fig. 2: Effects of CRYP on $\mathbf{4 5}$ signaling pathways. The relative expression levels of the 45 signaling pathways in HEK 293 cells after treatment with $5 \mu \mathrm{M}$ of CRYP was evaluated using the dual luciferase reporter gene assay. The results were expressed as log2 of the fold change of the expression of transcription factors between CRYP-treated cells and non-treated cells. The error bars represent standard deviation of three independent experiments conducted in duplicate wells.

\section{CRYP induces an increase in the transcript expression of IRF-1 and PR but decreases the transcript expression of HIF-1a and STAT3}

Having demonstrated at the luciferase reporter level that CRYP differentially regulates the 45 signaling pathways, two each of the upregulated pathways (namely IRF-1 and PR) and the downregulated pathways (namely HIF1-a and STAT3) were selected and further investigated using RT-qPCR. These genes were selected based on the fact that the anti-cancer therapeutic potential of CRYP targeting these 
genes have not been fully exploited. RT-qPCR analysis of the transcript levels of IRF-1, PR, HIF-1a and STAT3 in HEK 293 cells treated with increasing concentrations $(0,2.5$ and $5 \mu \mathrm{M})$ of CRYP was performed. It was observed that CRYP induced an increase in the transcript levels of IRF1 and PR in a dosedependent fashion. At $5 \mu \mathrm{M}$ CRYP, the transcript level of IRF-1 was increased by 9.4 folds (Fig. 3a) while the transcript level of PR was increased by 20.9 folds (Fig. 3b). On the other hand, CRYP inhibited the transcript levels of HIF-1 $a$ and STAT3. At 2.5 $\mu \mathrm{M}$ and 5 $\mathrm{MM}$ CRYP, the transcript levels of HIF-1a decreased by $70 \%$ and $60 \%$ respectively (Fig. 4 a). With reference to STAT3, $2.5 \mu \mathrm{M}$ of CRYP induced a $60 \%$ decrease in the transcript expression level. However, at $5 \mu \mathrm{M}$, CRYP had no significant detectable effects on the transcript expression level of STAT3 (Fig. 4b).

Fig. 3. CRYP induces an increase in the relative mRNA expression levels of (a) IRF1 and (b) PR in HEK 293 cells after treatment with increasing concentrations of $\operatorname{CRYP}(0,2.5$ and $5.0 \mu \mathrm{M})$. The relative mRNA expression levels of IRF1 and PR after normalization to B-actin (endogenous control) were expressed as means \pm standard deviations. The relative levels of IRF1 and PR were calculated using the relative standard curve method. The untreated cells $(0.0 \mu \mathrm{M})$ was used as reference group to estimate relative gene expression changes. For IRF-1, $* \star P$-value $<0.007, * \star \star \star P$-value $<0.0001$. For $\mathrm{PR}, \star \star *$-value $<0.02$, $\star \star \star \star *$-value $<0.0001$. The error bars represent standard deviations of triplicate wells in an experiment.

Fig. 4. CRYP induces a decrease in the relative mRNA expression levels of (a) HIF-1a and (b) STAT3 in HEK 293 cells after treatment with increasing concentrations of $\operatorname{CRYP}(0,2.5$ and $5.0 \mu \mathrm{M})$. The relative mRNA expression levels of HIF-1 $a$ and STAT3 after normalization to B-actin (endogenous control) were expressed as means \pm standard deviations. The relative levels of HIF-1 a and STAT3 were calculated using the relative standard curve method. The untreated cells $(0.0 \mu \mathrm{M})$ was used as reference group to estimate relative gene expression changes. For HIF-1a, ${ }^{\star \star} P$-value $<0.001$. For STAT3, ${ }^{\star \star} P$-value $<0.0004$. The error bars represent standard deviations of triplicate wells in an experiment.

\section{Discussion}

Cancer treatment is highly expensive and unaffordable by many especially in the low- and middle-income countries of the word. In addition to the high cost of treatments, toxic side effects associated with chemotherapy and radiation therapy have resulted in huge demand for cheaper and less toxic alternatives from natural sources (2). Making cancer treatments more effective and affordable especially in resource-limited countries including Ghana will greatly reduce cancer-induced deaths even in situations where health-care services are not well developed. In view of that natural products from plant sources that are basically used in traditional medicines especially in the resource-limited countries are being explored as one of the major sources of cancer chemo-preventive drug discovery. One of such plant products which is gaining much popularity as a potential anticancer agent is CRYP an alkaloid that is extracted from the roots of a plant called Cryptolepis sanguinolenta in the Western and Central parts of Africa. CRYP has been reported to exhibit anti-inflammatory activity and cytotoxic potential that is mediated through its direct and indirect interactions with DNA $(9,12,14,20,21)$. In the current study, we observed that treatment of HEK 293 cells with low concentration of CRYP induced a significant increase 
in the transcript expression levels of IRF-1 and PR but decreased transcript expression levels of HIF-1a and STAT 3.

IRF1 was initially discovered as a transcriptional activator of the interferon (IFN) system in response to viral infection $(22,23)$. However, evidence gathered after its initial discovery suggest that IRF1 also exhibits a myriad of cellular functions such as antitumor and immune regulatory properties (24-29). The antitumor properties of IRF1 are exhibited through its transcriptional regulation of antitumor genes and oncogenes (30). For example, IRF1 has been reported to induce an increase in the expression of antitumor genes, such as major histocompatibility complex I and II (MHC I \& II) $(31,32)$ and p53 $(33,34)$ but induces a reduction in the expression of tumour-promoting genes such as Cyclin D1(35) and survivin (36).Studies have also shown that the dysfunctioning of IRF1 has been linked to the development of several different types of cancers in humans (26). In fact, it has been reported in breast cancer patients that IRF1 expression is decreased in neoplastic breast tissues compared to normal counterparts (37). In addition, the mRNA expression level of IRF1 has been reported to be inversely linked to the grade of the tumour, risk of recurrence and death of breast cancer patients $(38,39)$. It has also been reported that the IRF1 expression level is reduced or completely lost in lymphoma and colon cancer $(40,41)$. Taken together, the above evidence strongly indicates anti-tumour roles of IRF1. It is a common knowledge that majority of drugs that are used in the treatment of human diseases including cancers have more than one target through which they exhibit their effects. Therefore, demonstration that CRYP induces an increased expression of the transcript level of IRF1 in the current study raises the possibility that IRF1 signalling could be one of the possible several ways through which CRYP could exhibit it anticancer mechanism and that CRYP or its analogues may be considered and developed as new anticancer agents.

The biological actions of PR signalling depend highly on the context. While some studies have reported that PR signalling promotes proliferation or differentiation, others have reported that PR signalling inhibits proliferation or differentiation depending on the conditions. In fact, some studies have reported that the role of PR signalling in breast tumour may be dependent on the stage of disease progression or the tumour type (42). Mohammed et al., (2012) reported that PR signalling can antagonize the proliferative effects of oestrogen in breast carcinomas (43). In addition, the presence of PR in primary breast carcinomas has been reported to be a marker of a very positive prognosis and is associated with a less aggressive cancer than PR negative tumours and that the presence of PR in the primary tumour is also associated with better overall survival $(44,45)$. Therefore, the ability of CRYP to induce an increase in the transcript expression level of PR could be targeted and exploited as a possible mechanism through which breast cancer can be treated.

HIF-1a is a major regulatory gene that is involved in the cells' response to a reduced oxygen supply. It plays a significant role in the progression and spread of tumour through activation of genes that are linked to the regulation of angiogenesis, cell survival, energy metabolism, and apoptotic and proliferative responses (46-48). Studies have shown that tumours that lack HIF-1a, tend to exhibit a significant reduction in vascularization and growth rates compared with normal cells $(49,50)$. In fact, HIF-1a has been reported to be overexpressed in many human malignancies, such as colon, breast, pancreas, 
prostate, kidney, stomach, and oesophageal cancers compared to their respective normal tissues (51-53). Thus, reports indicate that overexpression of HIF-1a is associated with poor clinical outcomes in patients with various cancers and that expression of HIF-1a is associated with poor survival in cervical cancer (54), endometrial carcinoma (55), oligodendroglioma (56), ovarian cancer (57) and different breast cancer subtypes (58-60). All these pieces of information point to the fact that therapeutic targeting of HIF$1 \mathrm{a}$ has the potential to improve cancer treatment efficacy and survival of cancer patients. Therefore, the demonstration that CRYP inhibits HIF-1a even at the transcript level suggests that CRYP could be exploited and developed as emerging and novel anti-cancer agents.

The multitude of evidence in the literature has shown that STAT3 plays a significant role in the development, progression and maintenance of many tumours in humans (61-65). An increase in the level of activated STAT3 has been shown to correlates with recurrent tumours and poor prognosis of many human cancers (66-68). Studies have shown that STAT-3 activated genes block apoptosis, promote cell proliferation and survival, enhance angiogenesis and metastasis and inhibit anti-tumour immune response $(62-65,69)$. On the other hand, available evidence suggests that any process or approach that disrupts STAT3 signalling may result in inhibition of growth and apoptosis in tumour cell lines and can inhibit tumour growth in mouse xenograft cancer models $(64,65,70-72)$. Therefore, the ability of CRYP to inhibit the transcript expression level of STAT3 at low concentration in the current study suggest that CRYP can be exploited further and developed as a cheaper and novel anti-cancer drug agent.

As to why the lower concentration of CRYP $(2.5 \mu \mathrm{M})$ induced a significant decrease in the transcript expression level of STAT3 but a relatively higher concentration $(5 \mu \mathrm{M})$ had no significant detectable effects on the transcript expression level of STAT3 is a subject for further research.

\section{Conclusions}

The current study identified some novel human pro- and anti-cancer signalling pathways regulated by CRYP in line with scientists' suspicion that CRYP has anti-cancer potential. The outcome of the current study offers promising avenues for further research into the development of CRYP as a novel anticancer agent. Achieving this feat would improve the treatment success of cancers and increase the chances of survival of cancer patients in low- and middle-income countries. Also, further studies are required to confirm the protein levels of all the genes reported in Fig. 2 of the current study.

\section{Abbreviations}

CRYP: Cryptolepine; IRF-1: Interferon regulatory factor-1; PR: Progesterone receptors; HIF-1a: Hypoxia inducible factor-1 alpha; STAT3: Signal transducer and activator of transcription 3; IARC: International agency for research on cancer; HBV: Hepatitis B virus; HCV: Hepatitis C virus; HPV: Human papillomavirus; DMEM: Dulbecco's modified eagles' medium; FBS: Foetal bovine serum; MEM: Minimum essential medium; NEAA: Non-essential amino acids; MTT: Thiazolyl blue tetrazolium bromide powder; 
HEK 293 cells: Human embryonic kidney cells; MHC I \& II: Major histocompatibility complex I and II; KNUST: Kwame Nkrumah University of Science and Technology

\section{Declarations}

\section{Data availability}

The raw datasets analyzed during the current study will be made available from the corresponding author on a reasonable request.

\section{Conflicts of interest}

The authors declare that they have no competing interests regarding the publications of this paper.

\section{Funding}

This work was supported with funds from a World Bank African Centres of Excellence grant (ACE02WACCBIP: Awandare) and a DELTAS Africa grant (DEL-15-007: Awandare). The DELTAS Africa Initiative is an independent funding scheme of the African Academy of Sciences (AAS)'s Alliance for Accelerating Excellence in Science in Africa (AESA) and supported by the New Partnership for Africa's Development Planning and Coordinating Agency (NEPAD Agency) with funding from the Wellcome Trust (107755/Z/15/Z: Awandare) and the UK government. The views expressed in this publication are those of the author(s) and not necessarily those of AAS, NEPAD Agency, Wellcome Trust or the UK government.

\section{Acknowledgments}

The authors sincerely thank Prof. Kwesi Mensah Boadu, Faculty of Pharmacy and Pharmaceutical Sciences, Kwame Nkrumah University of Science and Technology (KNUST), Kumasi, Ghana for providing the CRYP for this study. The authors also thank Prof. Tsiri Abenyega of the Department of Physiology, School of Medicine and Dentistry, KNUST for making available Applied Biosystems StepOne Plus Machine for the RT-qPCR experiment. We also thank everyone who contributed to this work in one way or the other.

\section{Authors' contributions}

MM and GA conceived the idea and designed the experiments. PWN and SAD performed the experiments, analyzed the data and wrote the manuscript. GA provided the funding for the study. All authors read and approved the final manuscript.

\section{Consent for publication}

Not applicable

\section{Ethics approval and consent to participate}




\section{References}

1. Ferlay J, Soerjomataram I, Ervik M, et al. GLOBOCAN 2012 v1.0, Cancer Incidence and Mortality Worldwide: IARC CancerBase No. 11 [Internet]. http://globocan.iarc.fr. Accessed December 12, 2013. 2013.

2. Cancer Research, UK, and IARC, 2011.

3. Kirby GC, Paine A, Warhurst DC, Noamese BK, Phillipson JD. In vitro and in vivo antimalarial activity of CRYP, a plant-derived indoloquinoline. Phytother Res. 1995;9, 359-363.

4. Gibbons S, Fallah F, Wright CW. CRYP hydrochloride: A potent antimycobacterial alkaloid derived from Cryptolepis sanguinolenta. Phytother Res. 2003;17, 434-436.

5. Sawer IK, Berry MI, Brown MW, Ford JL. The effect of CRYP on the morphology and survival of Escherichia coli, Candida albicans and Saccharomyces cerevisiae. J Appl Bacteriol. 1995;79, 314321.

6. Bierer DE, Fort DM, Mendez CD, Luo J, Imbach PA, Dubenko LG, et al. Ethnobotanical-directed discovery of the antihyperglycemic properties of CRYP: Its isolation from Cryptolepis sanguinolenta, synthesis, and in vitro and in vivo activities J Med Chem. 1998;41, 894-901.

7. Oyekan AO, Botting JH, Noamesi BK. CRYP inhibits platelet aggregation in vitro and in vivo and stimulates fibrinolysis ex vivo. Gen Pharmacol. 1998;19, 233-237.

8. Olajide OA, Ajayi AM, Wright CW. Anti-inflammatory properties of CRYP Phytother Res. 2009;23, 1421-1425.

9. Olajide OA, Bhatia HS, de Oliveira AC, Wright CW, Fiebich BL. Anti-neuroinflammatory properties of synthetic CRYP in human neuroblastoma cells: Possible involvement of NF-B and p38 MAPK inhibition Eur J Med Chem. 2013;63, 333-339.

10. Bonjean K, de Pauw-Gillet MC, Defresne MP, Colson P, Houssier C, Dassonneville L, et al. The DNA intercalating alkaloid CRYP interferes with topoisomerase II and inhibits primarily DNA synthesis in B16 melanoma cells Biochemistry. 1998;37,5136-5146.

11. Dassonneville L, Bonjean K, de Pauw-Gillet MC, Colson P, Houssier C, Quetin-Leclercq J, et al. Stimulation of topoisomerase II-mediated DNA cleavage by three DNA-intercalating plant alkaloids: CRYP, matadine, and serpentine. . Biochemistry 1999;38, 7719-7726.

12. Lisgarten JN, Coll M, Portugal J, Wright CW, Aymami J. The antimalarial and cytotoxic drug CRYP intercalates into DNA at cytosine-cytosine sites Nat Struct Biol. 2002;9, 57-60.

13. Kluza J, Lansiaux A, Wattez N, Mahieu C, Osheroff N, Bailly C. Apoptotic Response of HL-60 Human Leukemia Cells to the Antitumor Drug TAS-103. Cancer Res. 2000;6: 4077.

14. Pal HC, Katiyar SK. "Cryptolepine, a plant alkaloid, inhibits the growth of non-melanoma skin cancer cells through inhibition of topoisomerase and induction of DNA damage," Molecules. 2016;vol. 21, no. 12 , article 1758 . 
15. Zhu H, Gooderham NJ. Mechanisms of Induction of Cell Cycle Arrest and Cell Death by Cryptolepine in Human Lung Adenocarcinoma A549 Cells. Toxicol Sci. 2006;91: 132-139.

16. Li HL, Ye KH, Ren XD. Heparin induced apoptosis in human nasopharyngeal carcinoma CNE2 cells. Cell Res 2002b;11:311-315.

17. Li HL, Zhang HW, Ren XD. Synergism between heparin and adriamycin on cell proliferation and apoptosis in human nasopharyngeal carcinoma CNE2 cells. Acta Pharmacol Sin 2002a;23:167-172.

18. Ansah C, Gooderham NJ. The Popular herbal, antimalarial, Extract of Cryptolepis is potentially cytotoxic. Toxicol Sci. 2002;70:245-251.

19. Narkwa PW, Blackbourn DJ, Mutocheluh M. Aflatoxin B1 inhibits the type 1 interferon response pathway via STAT1 suggesting another mechanism of hepatocellular carcinoma. Infectious Agents and Cancer 2017;12:17

20. Laryea D, Isaksson A, Wright CW, Larsson R, Nygren P. Characterization of the cytotoxic activity of the indoloquinoline alkaloid CRYP in human tumour cell lines and primary cultures of tumour cells from patients. Investig New Drugs 2009;27, 402-411.

21. Matsui TA, Sowa Y, Murata H, Takagi K, Nakanishi R, Aoki S, et al. The plant alkaloid CRYP induces p21WAF1/CIP1 and cell cycle arrest in a human osteosarcoma cell line. Int J Oncol. 2007;31, 915922.

22. Harada H, Fujita T, Miyamoto M, Kimura Y, Maruyama M, Furia A, et al. Structurally similar but functionally distinct factors, IRF-1 and IRF-2, bind to the same regulatory elements of IFN and IFNinducible genes Cell 1989;58:729-739.

23. Miyamoto $M$, Fujita T, Kimura $Y$, Maruyama $M$, Harada $H$, Sudo $Y$, et al. Regulated expression of a gene encoding a nuclear factor, IRF-1, that specifically binds to IFN-beta gene regulatory elements. Cell. 1988;54:903-913.

24. Kirchhoff S, Schaper F, Hauser $\mathrm{H}$. Interferon regulatory factor 1 (IRF-1) mediates cell growth inhibition by transactivation of downstream target genes. Nucleic Acids Res 1993;21, 2881-2889.

25. Kroger A, Dallugge A, Kirchhoff S, Hauser H. IRF-1 reverts the transformed phenotype of oncogenically transformed cells in vitro and in vivo. Oncogene. 2003;22,1045-1056.

26. Mamane $Y$, Heylbroeck C, Genin P, Algarte M, Servant MJ, LePage C, et al. Interferon regulatory factors: the next generation. Gene 1999;237,1-14.

27. Tamura T, Ishihara M, Lamphier MS, Tanaka N, Oishi I, Aizawa S, et al. An IRF-1-dependent pathway of DNA damage-induced apoptosis in mitogenactivated T lymphocytes. Nature 1995;376,596-599.

28. Tanaka N, Kawakami T, Taniguchi T. Recognition DNA sequences of interferon regulatory factor 1 (IRF-1) and IRF-2, regulators of cell growth and the interferon system Mol Cell Biol. 1993;13,45314538.

29. Taniguchi T, Ogasawara K, Takaoka A, Tanaka N. IRF family of transcription factors as regulators of host defense. Annu Rev Immunol. 2001;19,623-655. 
30. AbuSara N, Razavi S, Derwish L, Komatsu Y, Licursi M, Hirasawa K. Restoration of IRF1-dependent anticancer effects by MEK inhibition in human cancer cells Cancer Letters 2015;357:575-581.

31. Chang $\mathrm{CH}$, Hammer J, Loh JE, Fodor WL, Flavell RA. The activation of major histocompatibility complex class I genes by interferon regulatory factor-1 (IRF-1). Immunogenetics 1992;35,378-384.

32. Yim JH, Wu SJ, Casey MJ, Norton JA, Doherty GM. IFN regulatory factor-1 gene transfer into an aggressive, nonimmunogenic sarcoma suppresses the malignant phenotype and enhances immunogenicity in syngeneic mice. J Immunol. 1997;158,1284-1292.

33. Gao J, Senthil M, Ren B, Yan J, Xing Q, Yu J, et al. IRF-1 transcriptionally upregulates PUMA, which mediates the mitochondrial apoptotic pathway in IRF-1-induced apoptosis in cancer cells Cell Death Differ. 2010;17,699-709.

34. Wang J, Zhang W, Zhang Y, Chen Y, Zou B, Jiang B, et al. c-Jun N-terminal kinase (JNK1) upregulates XIAP-associated factor 1 (XAF1) through interferon regulatory factor 1 (IRF-1) in gastrointestinal cancer. Carcinogenesis 2009;30,222-229.

35. Kroger A, Stirnweiss A, Pulverer JE, Klages K, Grashoff M, Reimann J, et al. Tumor suppression by IFN regulatory factor- 1 is mediated by transcriptional down-regulation of cyclin D1. Cancer Res. 2007;67,2972-2981.

36. Pizzoferrato JE, Liu Y, Gambotto A, Armstrong MJ, Stang MT, Gooding WE, et al. Ectopic expression of interferon regulatory factor-1 promotes human breast cancer cell death and results in reduced expression of survivin. Cancer Res. 2004; 64,8381-8388.

37. Doherty GM, Boucher L, Sorenson K, Lowney J. Interferon regulatory factor expression in human breast cancer. Oncogene. 2003;22,381-391.

38. Cavalli LR, Riggins RB, Wang A, Clarke R, Haddad BR. Frequent loss of heterozygosity at the interferon regulatory factor-1 gene locus in breast cancer. Breast Cancer Res Treat. 2010;121,227231.

39. Connett JM, Badri L, Giordano TJ, Connett WC, Doherty GM. Interferon regulatory factor 1 (IRF-1) and IRF-2 expression in breast cancer tissue microarrays. J Interferon Cytokine Res. 2005;25,587-594.

40. Ogasawara S, Tamura G, Maesawa C, Suzuki Y, Ishida K, Satoh N, et al. Common deleted region on the long arm of chromosome 5 in esophageal carcinoma. Gastroenterology 1996;110,52-57.

41. Willman CL, Sever CE, Pallavicini MG, Harada H, Tanaka N, Slovak ML, et al. Deletion of IRF-1, mapping to chromosome 5q31.1, in human leukemia and preleukemic myelodysplasia. Science $1993 ; 259,968-971$.

42. Grimm SL, Hartig SM, Edwards DP. Progesterone Receptor Signaling Mechanisms. J Mol Biol. 2016;428, 3831-3849.

43. Mohammed H, Russell IA, Stark R, Rueda OM, Hickey TE, Tarulli GA, et al. Progesterone receptor modulates ERalpha action in breast cancer. Nature 2015;523,313-317.

44. Bardou VJ, Arpino G, Elledge RM, Osborne CK, Clark GM. Progesterone receptor status significantly improves outcome prediction over estrogen receptor status alone for adjuvant endocrine therapy in two large breast cancer databases. J Clin Oncol. 2003;21,1973-1979. 
45. Baum M, Buzdar A, Cuzick J, Forbes J, Houghton J, Howell A, et al. Anastrozole alone or in combination with tamoxifen versus tamoxifen alone for adjuvant treatment of postmenopausal women with early-stage breast cancer: results of the ATAC (arimidex, tamoxifen alone or in combination) trial efficacy and safety update analyses. Cancer. 2003;98,1802-1810.

46. Carmeliet P, Dor Y, Herbert JM, Fukumura D, Brusselmans K, Dewerchin M, et al. Role of HIF-1 a in hypoxia-mediated apoptosis, cell proliferation and tumour angiogenesis. Nature. 1998;394:485-490.

47. Vaupel P. The role of hypoxia-induced factors in tumor progression. Oncologist 9. 2004;(Suppl 5):1017.

48. Wang GL, Semenza GL. Purification and characterization of hypoxia-inducible factor 1. J Biol Chem 1995;270: 1230-1237.

49. Kung AL, Wang S, Klco JM, Kaelin WG, Livingston DM. Suppression of tumor growth through disruption of hypoxia-inducible transcription. Nat Med 2000;6:1335-1340.

50. Ryan HE, Poloni M, McNulty W, Elson D, Gassmann M, Arbeit JM, et al. Hypoxiainducible factor-1 alpha is a positive factor in solid tumor growth. Cancer Res 2000;60:4010-4015.

51. Daponte A, loannou M, Mylonis I, Simos G, Minas M, Messinis IE, et al. Prognostic significance of hypoxia-inducible factor $1 \mathrm{a}(\mathrm{HIF-1a)}$ expression in serous ovarian cancer: an immunohisto-chemical study. BMC Cancer. 2008;8: 335.

52. Mayer A, Hockel M, Wree A, Leo C, Horn LC, Vaupel P. Lack of hypoxic response in uterine leiomyomas despite severe tissue hypoxia. Cancer Res 2008b;68,4719-4726.

53. Simiantonaki N, Taxeidis M, Jayasinghe C, Kurzik-Dumke U, Kirkpatrick CJ. Hypoxia-inducible factor 1 alpha expression increases during colorectal carcinogenesis and tumor progression. BMC Cancer $2008 ; 8,320$.

54. Birner $P$, Schindl M, Obermai A, et al. Overexpression of hypoxia-inducible factor 1 . is a marker for an unfavorable prognosis in early-stage invasive cervical cancer. Cancer Res 2000;60:4693-4696.

55. Sivridis E, Giatromanolaki A, Gatter KC, Harris AL, Koukourakis MI. Association of hypoxia-inducible factors 1aand 2awithactivated angiogenic pathways and prognosis in patients withendometrial carcinoma. Cancer. 2002;95: 1055-1063.

56. Birner P, Gatterbauer B, Oberhuber G, Schindl M, Rö ssler K, Prodinger A, et al. Expression of hypoxiainducible factor-1 ain oligodendrogliomas: its impact on prognosis and onneoangiogenesis. Cancer. 2001a;92: 165-171.

57. Birner P, Schindl M, Obermair A, Breitenecker G, Oberhuber G. Expression of hypoxia-inducible factor 1ain epithelialovarian tumors: its impact on prognosis and on response tochemotherapy. Clin Cancer Res. 2001b;7: 1661-1668.

58. Bos R, van der Groep P, Greijer AE, et al. Levels of hypoxiainducible factor-1 - independently predict prognosis in patients with lymph node negative breast carcinoma. Cancer 2003;97: 1573-1581.

59. Generali D, Berruti A, Brizzi MP, Campo L, Bonardi S, Wigfield S, et al. Hypoxia-inducible factor1 aexpression predicts a poorresponse to primary chemoendocrine therapy and disease-freesurvival in primary human breast cance. Clin Cancer Res. 2006;12:4562-4568. 
60. Kronblad A, Jirstrom K, Ryden L, Nordenskjold B, Landberg G. Hypoxia inducible factor-1 ais a prognostic marker inpremenopausal patients with intermediate to highly differentiatedbreast cancer but not a predictive marker for tamoxifen response. Int J Cancer. 2006;118: 2609-2616.

61. Aggarwal BB, Kunnumakkara AB, Harikumar KB, Gupta SR, Tharakan ST, Koca C, et al. Signal transducer and activator of transcription-3, inflammation, and cancer: how intimate is the relationship? . Ann N Y Acad Sci 2009;1171:59-79.

62. Frank DA. STAT3 as a central mediator of neoplastic cellular transformation. Cancer Letters 2007;251:199-210.

63. Germain D, Frank DA. Targeting the cytoplasmic and nuclear functions of signal transducers and activators of transcription 3 for cancer therapy. Clin Cancer Res. 2007;13:5665-5669.

64. Jing N, Tweardy DJ. Targeting Stat3 in cancer therapy. Anticancer Drugs 2005;16:601-607.

65. Leeman RJ, Lui VW, Grandis JR. STAT3 as a therapeutic target in head and neck cancer. Expert Opin Biol Ther 2006; 6:231-241.

66. Duan Z, Foster R, Bell DA, Mahoney J, Wolak K, Vaidya A, et al. Signal transducers and activators of transcription 3 pathway activation in drug-resistant ovarian cancer. Clin Cancer Res 2006;12: 50555063.

67. Rosen DG, Mercado-Uribe I, Yang G, Bast RCJ, Amin HM, Lai R, et al. The role of constitutively active signal transducer and activator of transcription 3 in ovarian tumorigenesis and prognosis. Cancer 2006;107: 2730-2740.

68. Silver DL, Naora H, Liu J, Cheng W, Montell DJ. Activated signal transducer and activator of transcription (STAT) 3: localization in focal adhesions and function in ovarian cancer cell motility. Cancer Res 2004;64: 3550-3558.

69. Regis G, Pensa S, Boselli D, Novelli F, Poli V. Ups and downs: the STAT1:STAT3 seesaw of Interferon and gp130 receptor signalling. Semin Cell Dev Biol 2008;19:351-359.

70. Fletcher S, Drewry JA, Shahani VM, Page BD, Gunning PT. Molecular disruption of oncogenic signal transducer and activator of transcription 3 (STAT3) protein. Biochem Cell Biol 2009; 87:825-833.

71. Leeman-Neill RJ, Wheeler SE, Singh SV, Thomas SM, Seethala RR, Neill DB, et al. Guggulsterone enhances head and neck cancer therapies via inhibition of signal transducer and activator of transcription-3. Carcinogenesis. 2009;30:1848-1856.

72. Zhang C, Li B, Zhang X, Hazarika P, Aggarwal BB, Duvic M. Curcumin selectively induces apoptosis in cutaneous T-cell lymphoma cell lines and patients' PBMCs: potential role for STAT-3 and NF-kappaB signaling. J Invest Dermatol 2010;130:2110-2119.

\section{Figures}




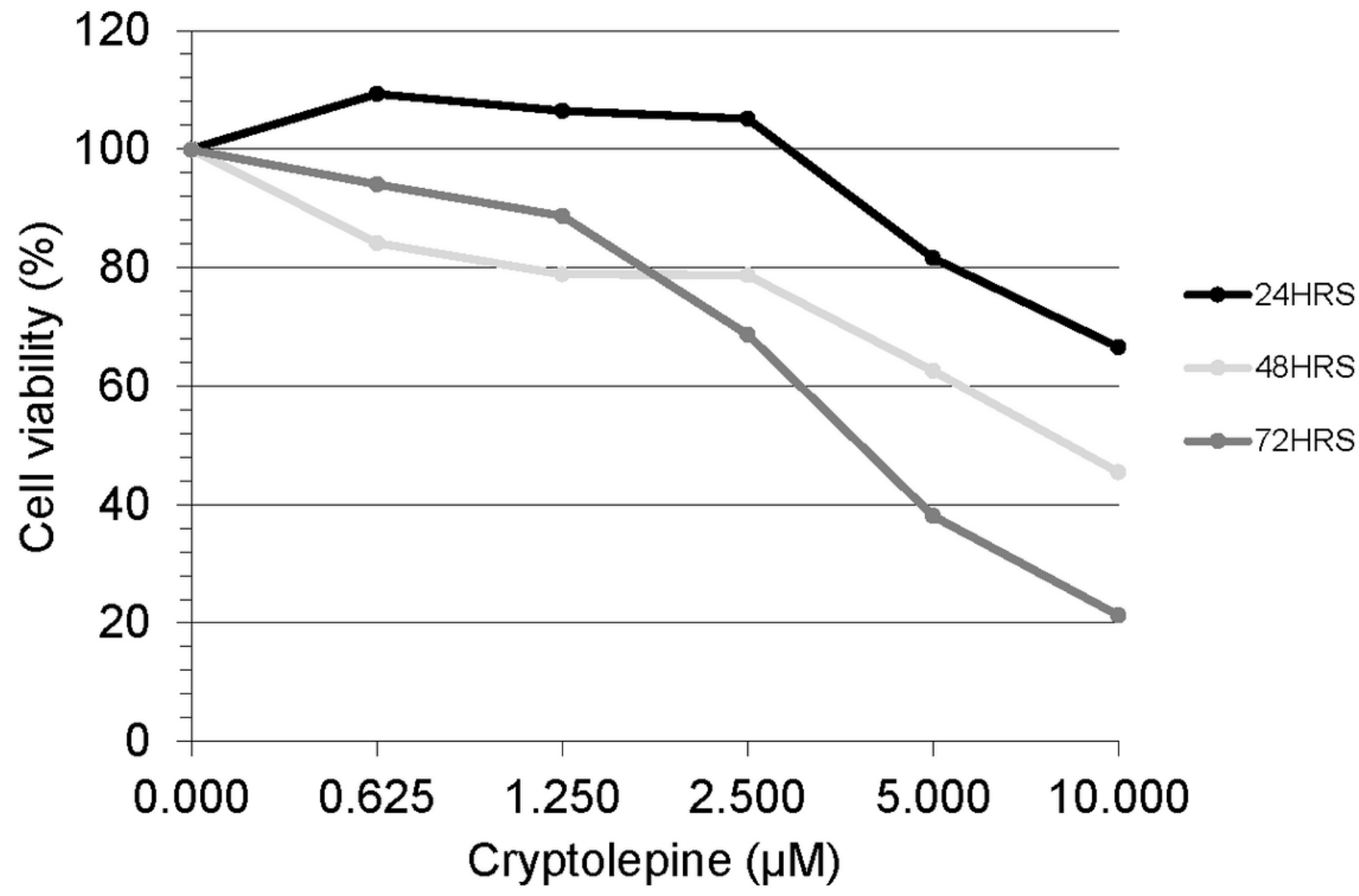

Figure 1

HEK 293 cells and cytotoxicity of CRYP. CRYP cytotoxicity was evaluated by MTT assay on HEK 293 cells treated with CRYP $(0-10 \mu \mathrm{M})$ for 24,48 and 72 hours. The viability of cells was calculated as the ratio between CRYP-treated cells and non-treated cells (equal volume of PBS replacing CRYP). Data are presented as mean and standard deviation of three independent experiments each performed in triplicate wells, $p$-value $=0.03$ as determined by one-way ANOVA. The error bars represent the standard deviation among the three independent experiments but are too small to show. 


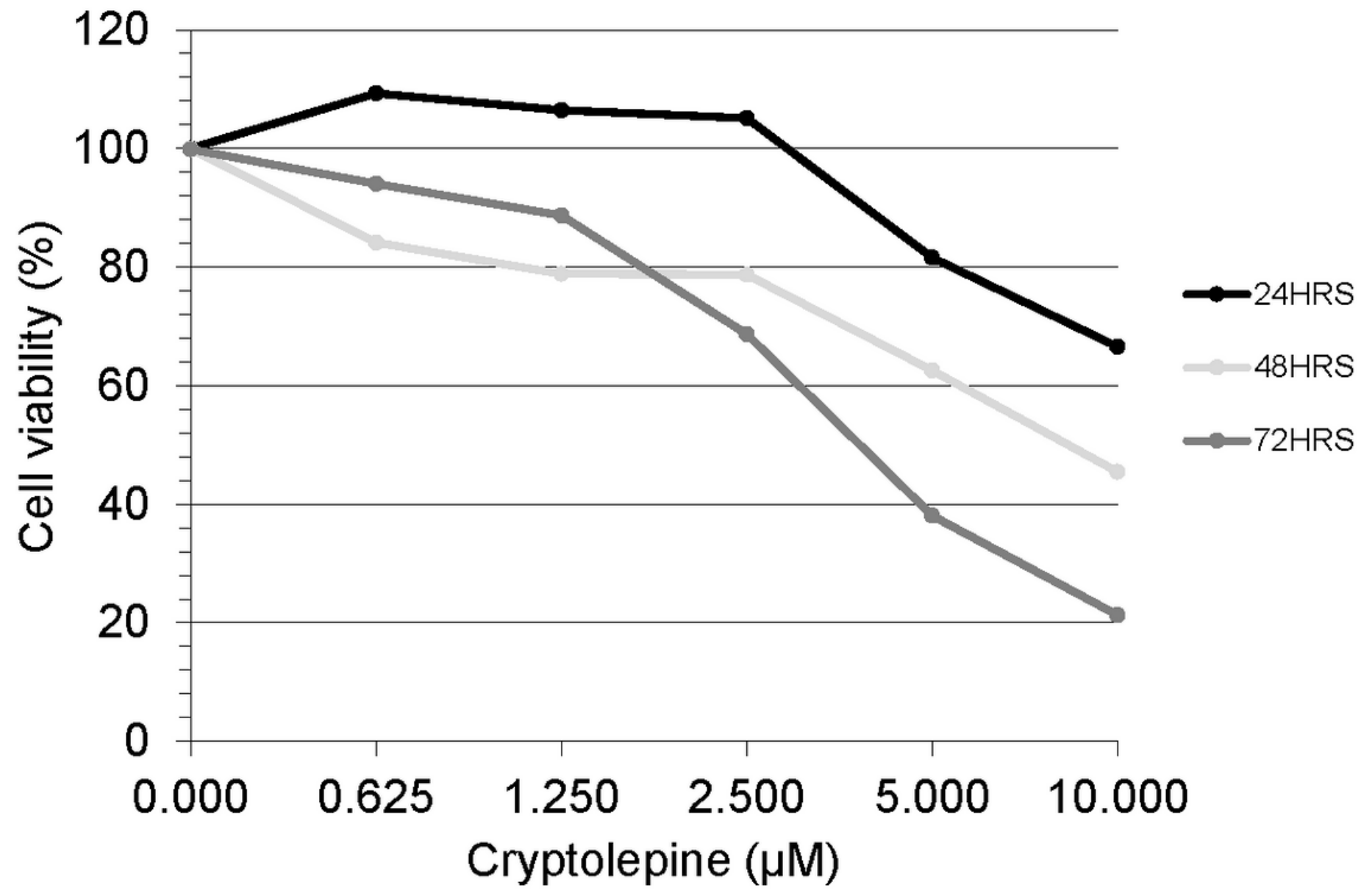

Figure 1

HEK 293 cells and cytotoxicity of CRYP. CRYP cytotoxicity was evaluated by MTT assay on HEK 293 cells treated with CRYP $(0-10 \mu \mathrm{M})$ for 24,48 and 72 hours. The viability of cells was calculated as the ratio between CRYP-treated cells and non-treated cells (equal volume of PBS replacing CRYP). Data are presented as mean and standard deviation of three independent experiments each performed in triplicate wells, $p$-value $=0.03$ as determined by one-way ANOVA. The error bars represent the standard deviation among the three independent experiments but are too small to show. 


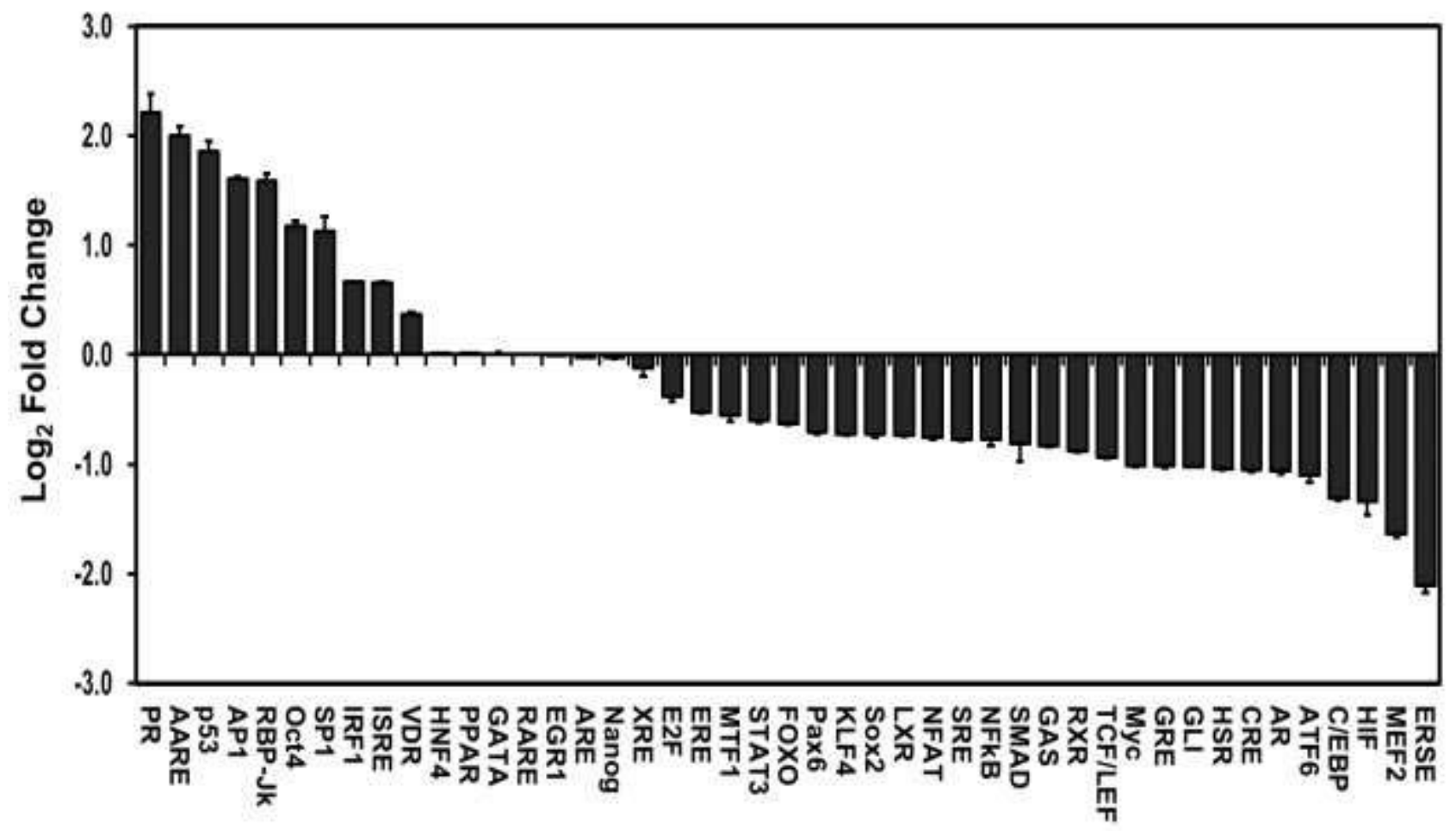

Figure 2

Effects of CRYP on 45 signaling pathways. The relative expression levels of the 45 signaling pathways in HEK 293 cells after treatment with $5 \mu \mathrm{M}$ of CRYP was evaluated using the dual luciferase reporter gene assay. The results were expressed as log2 of the fold change of the expression of tran scription factors between CRYP-treated cells and non-treated cells.

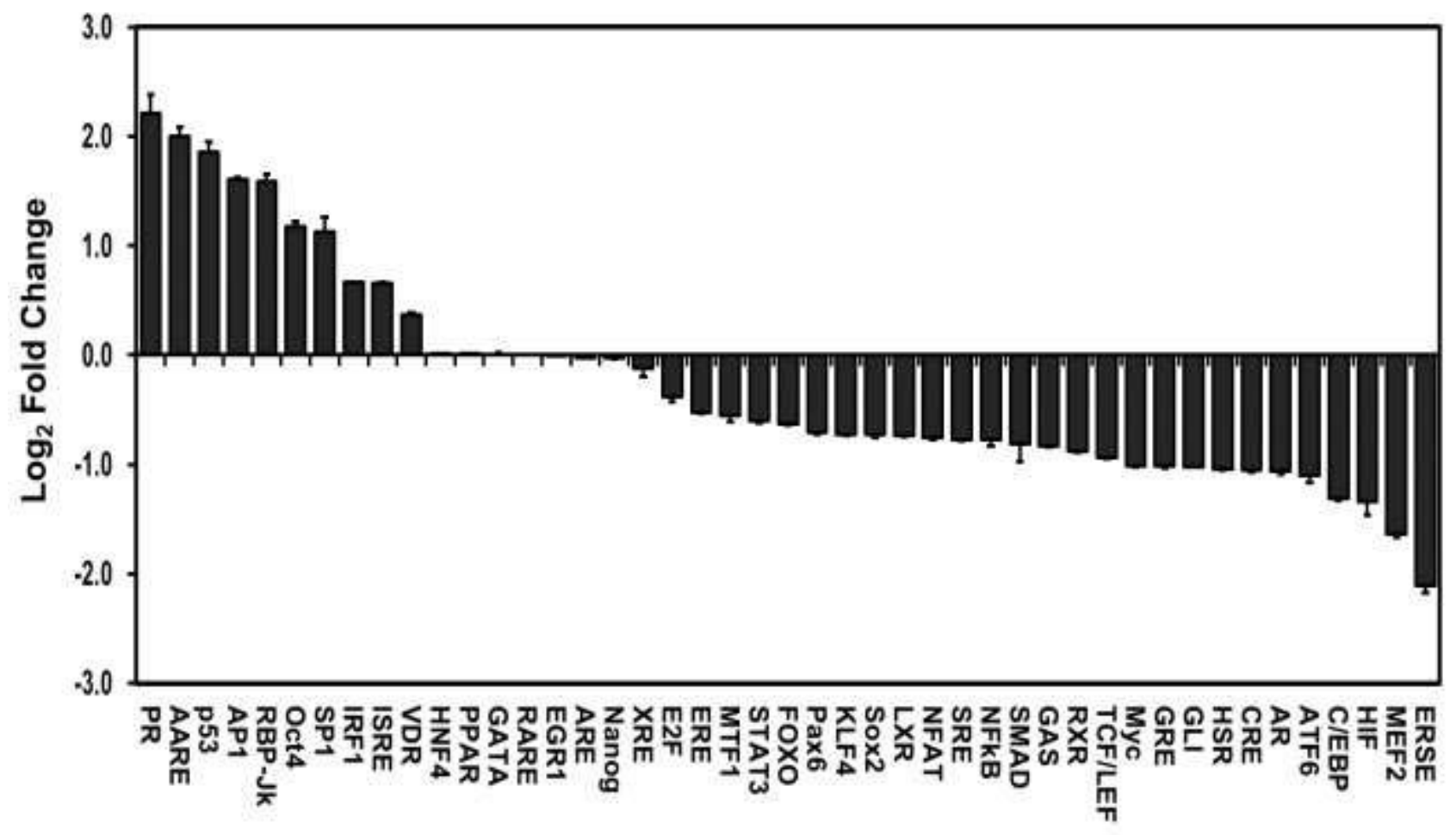

Figure 2 
Effects of CRYP on 45 signaling pathways. The relative expression levels of the 45 signaling pathways in HEK 293 cells after treatment with $5 \mu \mathrm{M}$ of CRYP was evaluated using the dual luciferase reporter gene assay. The results were expressed as log2 of the fold change of the expression of tran scription factors between CRYP-treated cells and non-treated cells.
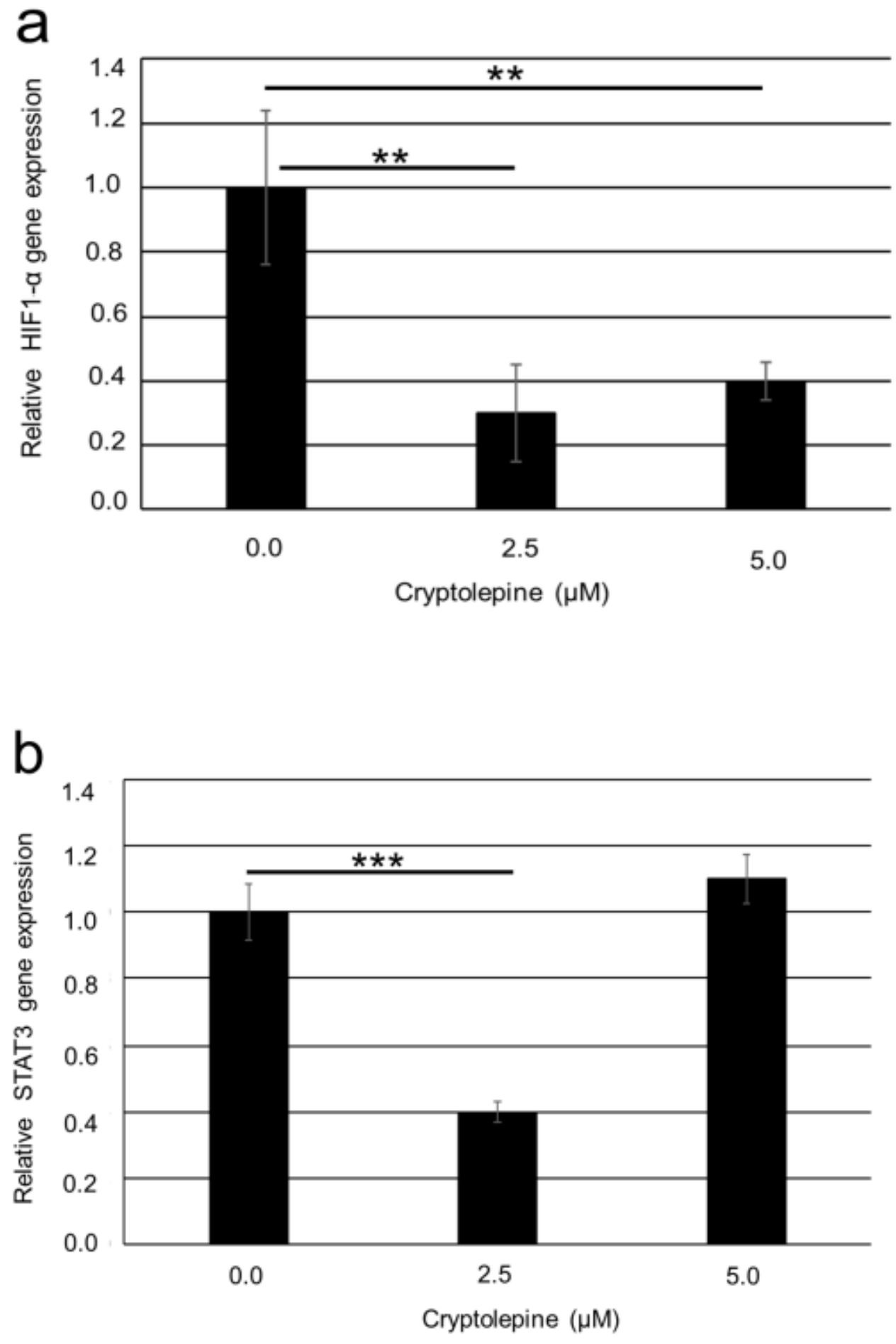

Figure 3 
CRYP induces a decrease in the relative mRNA expression levels of (a) HIF-1a and (b) STAT3 in HEK 293 cells after treatment with increasing concentrations of $\operatorname{CRYP}(0,2.5$ and $5.0 \mu \mathrm{M})$. The relative mRNA expression levels of HIF-1a and STAT3 after normalization to B-actin (endogenous control) were expressed as means \pm standard deviations. The relative levels of HIF-1 a and STAT3 were calculated using the relative standard curve method. The untreated cells $(0.0 \mu \mathrm{M})$ were used as reference group to

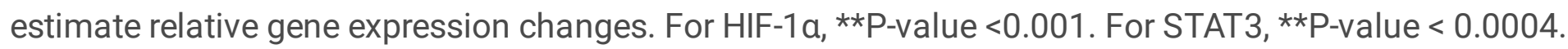
The error bars rep resent standard deviations of triplicate wells in an experiment.
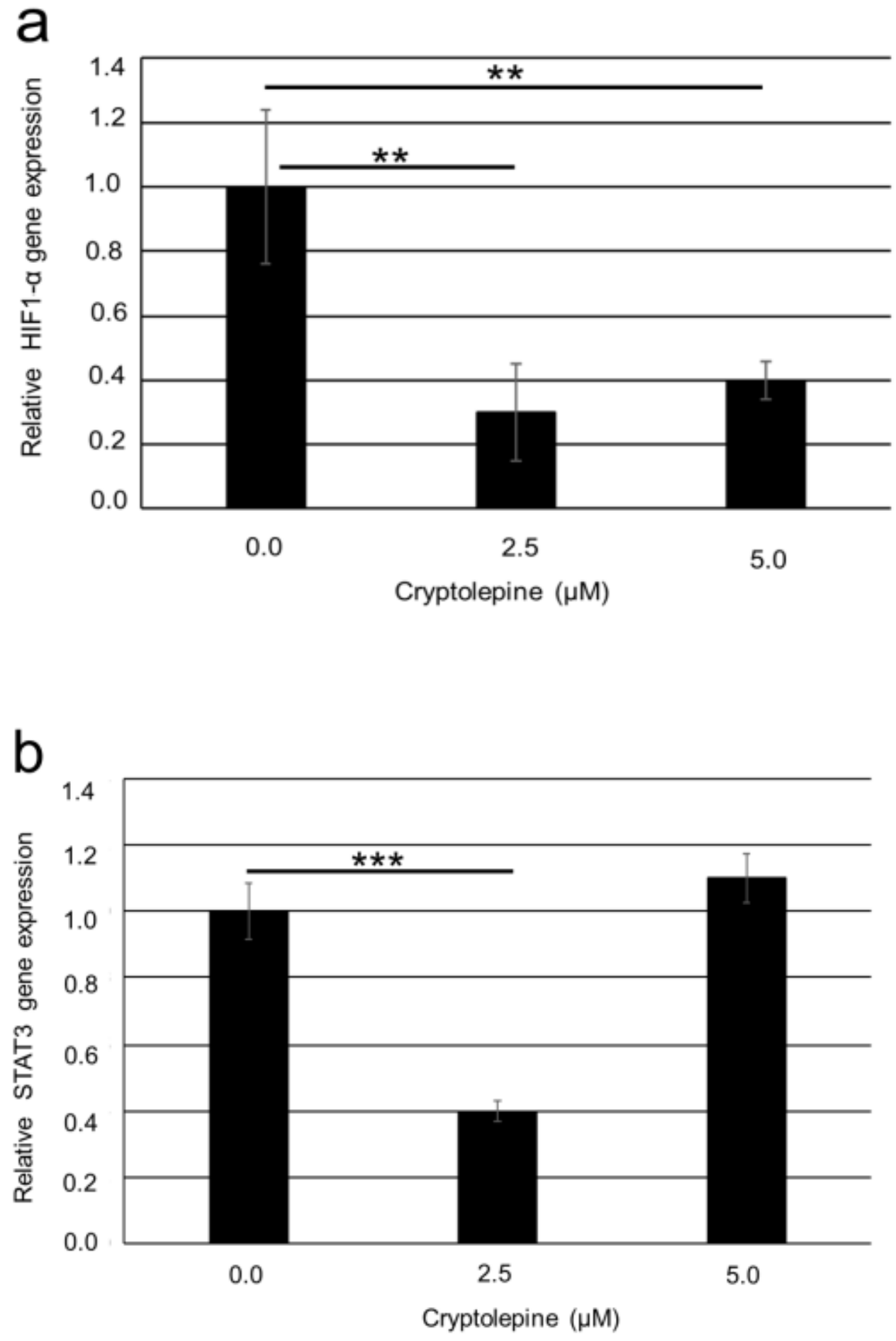


\section{Figure 3}

CRYP induces a decrease in the relative mRNA expression levels of (a) HIF-1a and (b) STAT3 in HEK 293 cells after treatment with increasing concentrations of $\operatorname{CRYP}(0,2.5$ and $5.0 \mu \mathrm{M})$. The relative mRNA expression levels of HIF-1 a and STAT3 after normalization to B-actin (endogenous control) were expressed as means \pm standard deviations. The relative levels of HIF-1a and STAT3 were calculated using the relative standard curve method. The untreated cells $(0.0 \mu \mathrm{M})$ were used as reference group to estimate relative gene expression changes. For HIF-1a, ${ }^{*}$ P-value $<0.001$. For STAT3, ${ }^{\star * P}$-value $<0.0004$. The error bars rep resent standard deviations of triplicate wells in an experiment.

\section{Supplementary Files}

This is a list of supplementary files associated with this preprint. Click to download.

- ADDITIONALFILE1.xIsx

- ADDITIONALFILE1.xIsx

- ADDITIONALFILE2.xIsx

- ADDITIONALFILE2.xIsx 